\title{
ENTRADAS A LA ACTIVIDAD, SALIDAS Y VIDA MEDIA ACTIVA EN MÉXICO, 1960-1965
}

\author{
José B. Morelos * \\ El Colegio de México
}

El PROPósito de este estudio es analizar, desde un punto de vista cuantitativo, las características demográficas de la población considerada como factor de la producción, o, lo que es lo mismo, como insumo de importancia en el proceso productivo. Por lo tanto, el objeto del análisis está integrado por "aquella parte de la población que participa o desea participar en la producción de bienes y servicios, incluyendo además de las diferentes categorías de trabajador, a los desocupados y a los que buscan trabajo por primera vez". 1 A este subconjunto de la población se le denomina población económicamente activa.

En primer término, se examinan las relaciones entre la población activa y la total. En el caso de la primera se ha supuesto que los niveles de participación de 1960 permanecerán constantes hasta 1965. Este supuesto se basa en que las variaciones que experimenten las tasas de actividad de algunos grupos de edad (principalmente los grupos menores de 20 años y mayores de 55 años) no serán tan importantes como para modificar los resultados. A continuación se analizan sus componentes de cambio, o sea las entradas a la actividad y las salidas de ésta por retiro o muerte, según edad, sexo y lugar de residencia.

Hasta ahora, los componentes de cambio en algunos países latinoamericanos se han analizado sólo con relación a la población masculina y sin considerar el lugar de residencia; se han elaborado para ello tablas de vida activa. ${ }^{2}$ En el caso presente, se ha extendido el análisis: a la población femenina, no obstante presentar ésta algunos problemas de tipo metodológico. La lógica del método de estimación supone que los retiros ocurren sólo por vejez, jubilación u otras causas de menor importancia numérica, mientras que en la población femenina las separaciones de la actividad, en determinados grupos de edad

* El autor agradece la colaboración de Alan Kay, quien tuvo a su cargo la preparación de la mayor parte del material estadístico.

1 La definición corresponde a la utilizada en el VIII Censo General de Población, Resumen General, México, 1960, pp. XLIX y L.

Asimismo en el presente estudio se emplearán con igual significado los conceptos de población activa y mano de obra.

2 En una investigación dirigida por el Profesor Jorge Somoza y realizada en el Centro Latinoamericano de Demografía en 1966, el autor estimó las entradas y salidas a la actividad sin construir la tabla de vida activa. La metodología que en esa ocasión se utilizó es la que ahora se emplea en la presente investigación. 
(20 a 39), se deben principalmente a cambios en su estado civil, a los riesgos inherentes a tales cambios y a las responsabilidades propias de su nuevo estado. Pese a estas limitaciones los resultados obtenidos son satisfactorios y coherentes.

En segundo lugar, para complementar el examen de la población activa se hace un breve análisis de la duración de la vida activa en 1960, por edad, sexo y lugar de residencia. Toda esta información contribuye a una mayor comprensión de las características demográficas de la mano de obra.

En la presente investigación se utilizó información proveniente de una muestra del censo de población de 1960, que en 1964 realizó el Centro de Estudios Económicos y Demográficos del Colegio de México. ${ }^{3}$ Dicha muestra, del $1.5 \%$ del total de las tarjetas perforadas que se utilizaron en la elaboración del censo de 1960, ha permitido elaborar una serie de tabulaciones especiales de la población económicamente activa. ${ }^{4} \mathrm{La}$ información sobre población total por sexo y lugar de residencia, corregida y proyectada a 1965, que sirve de base para calcular y proyectar la población activa y las entradas y salidas a la actividad, se tomó del trabajo de Benítez Zenteno y Cabrera.5

\section{RELACIÓN ENTRE POBLACIÓN ACTIVA Y POBLACIÓN TOTAL}

En el supuesto de que las condiciones de actividad se mantengan constantes, las variaciones que experimente la población activa dependerán del monto y la estructura de la población total. En poblaciones como la de México, cuyas características son su rejuvenecimiento y su rápido crecimiento - condicionadas por el comportamiento a largo plazo de la natalidad, la mortalidad y las migraciones- ${ }^{6}$ la población activa tiende a crecer a un ritmo inferior al de la población total. ${ }^{7}$ Este crecimiento diferencial explica el aumento que experimenta, en el período estudiado, la relación de dependencia, o, lo que es lo mismo, la disminución de la proporción de la población activa respecto a la población total (tasa bruta de actividad). En el área urbana, esta última pasó de $31.0 \%$ en 1960 a $29.7 \%$ en 1965. En los mismos años, el descenso de este indicador en el área rural fue menor. De $29.1 \%$ bajó a $28.9 \%$. Característica similar se observa tanto en los hombres como en las mujeres.

3 En el apéndice I se considera brevemente la calidad y representatividad de la muestra.

4 Para mayor información sobre el diseño y obtención de la muestra, véase El Colegio de México, Centro de Estudios Económicos y Demográficos, Estudios de población y fuerza de trabajo, México, 1966 (mimeografiado), pp. 2 a 5.

5 Raúl Benítez Zenteno y Gustavo Cabrera Acevedo, Proyecciones de la población de México, 1960-1980. México, Banco de México, 1966.

6 En México, en las últimas décadas, el rejuvenecimiento y el rápido crecimiento han sido determinados en parte por la disminución de los niveles de mortalidad. En 1930, la tasa de mortalidad era del orden de 27 por mil y en la actualidad es del orden del 9 por mil. Por otro lado, han influido los niveles altos y constantes de la natalidad, del orden de $42-47$ por mil durante el mismo período.

7 Horace Belshaw, Population Growth and Levels of Consumption, Londres, George Allen and Unwin, 1960, pp. 53-54; S. A. Wolfbein y J. A. Jaffe, "Demographic Factors in Labor Force Growth", en Spengler y Duncan, Demographic Analysis. Nueva York, The Free Press of Glencoe, 1963, pp. 492-496. 
Asimismo, los distintos tipos de estructura ${ }^{8}$ de población determinan límites máximos de participación, sobre todo en la población masculina. En los países con estructura joven, la proporción de hombres activos entre 15 y 64 años de edad es menor que en los países con población envejecida o en proceso de envejecimiento. En estos últimos, la proporción es del orden de 58 a $70 \%$, mientras que en los primeros es de 48 a $54 \%$. En México, es de $48.8 \%$ en el área urbana y de $49.9 \%$ en la rural. En cuanto a la población femenina las diferencias entre los países son más marcadas; en este caso la determinación de los límites máximos de participación obedece en mayor grado a los factores económicos y sociales $^{9}$ que a la estructura por edades de la población.

De igual modo, los factores económicos y sociales influyen en la existencia de bajos o altos niveles de participación en las edades marginales o sea los grupos menores de 20 años y mayores de 55. En los países actualmente desarrollados, la extensión y la prolongación de la escolaridad, la urbanización, el progreso técnico y la legislación social y del trabajo ${ }^{10}$ determinan un nivel bajo de participación en estas edades. Por el contrario, en los países en proceso de desarrollo el nivel relativamente mayor de participación en estos grupos de edad obedece al elevado porciento de la población dedicada a actividades agrícolas, a los bajos niveles de escolaridad y alfabetismo, al menor progreso técnico y a la aplicación apenas limitada de la legislación social y del trabajo.

A nivel nacional, aunque en forma menos marcada, se dan también estas diferencias en los niveles de participación. Lo anterior tiene vigencia tanto entre entidades con diferente nivel de desarrollo como entre la población urbana y la rural. En México, por ejemplo, el elevado porciento $(80-90 \%)$ de la población activa rural que se dedica a la agricultura, la mayor proporción de población analfabeta $(61.3 \%)$ y la menor inscripción de la población en edad escolar (6-14 años $)^{11}$ determinan niveles mayores de participación en las edades marginales de la población rural. (Véase la gráfica 1.)

Es de esperar, sin embargo, que estas diferencias disminuyan como consecuencia de futuros cambios de la estructura ocupacional de la población activa. El que más influencia ejercerá en el grado de participación de la población activa será la disminución de la importancia relativa de la mano de obra en el sector agrícola. Esta transformación significa mayor proporción de la población en actividades urbanas, mayor asistencia escolar y una disminución de la participación en las edades marginales. Este supuesto se basa en la evidencia

8 Se reconocen tres tipos de estructura por edad: a) estructura joven, cuya proporción de población menor de 15 años es de 40 a $50 \% ; b$ ) población envejecida, en la cual la proporción de población menor de 15 años es de 18 a $30 \%$; y c) población en proceso de envejecimiento, en la que la proporción de población - menor de 15 años tiene valor intermedio entre $a$ ) y $b$ ).

9 Naciones Unidas, Aspectos demográficos de la mano de obra. Estudios sobre población, Núm. 33, ST/SOA/Ser. A/33. Nueva York, 1963, pp. 438.

$10 \mathrm{~J}$. C. Elizaga, Población económicamente activa. Serie A, E/CN/CELADE/ A.13 C.59/2 Rev. 1, Santiago de Chile, 1964, p. 22.

11 En el área urbana, la tasa de inscripción escolar de la población de 6 a 14 años es $45.4 \%$ mayor que la de la población rural. 


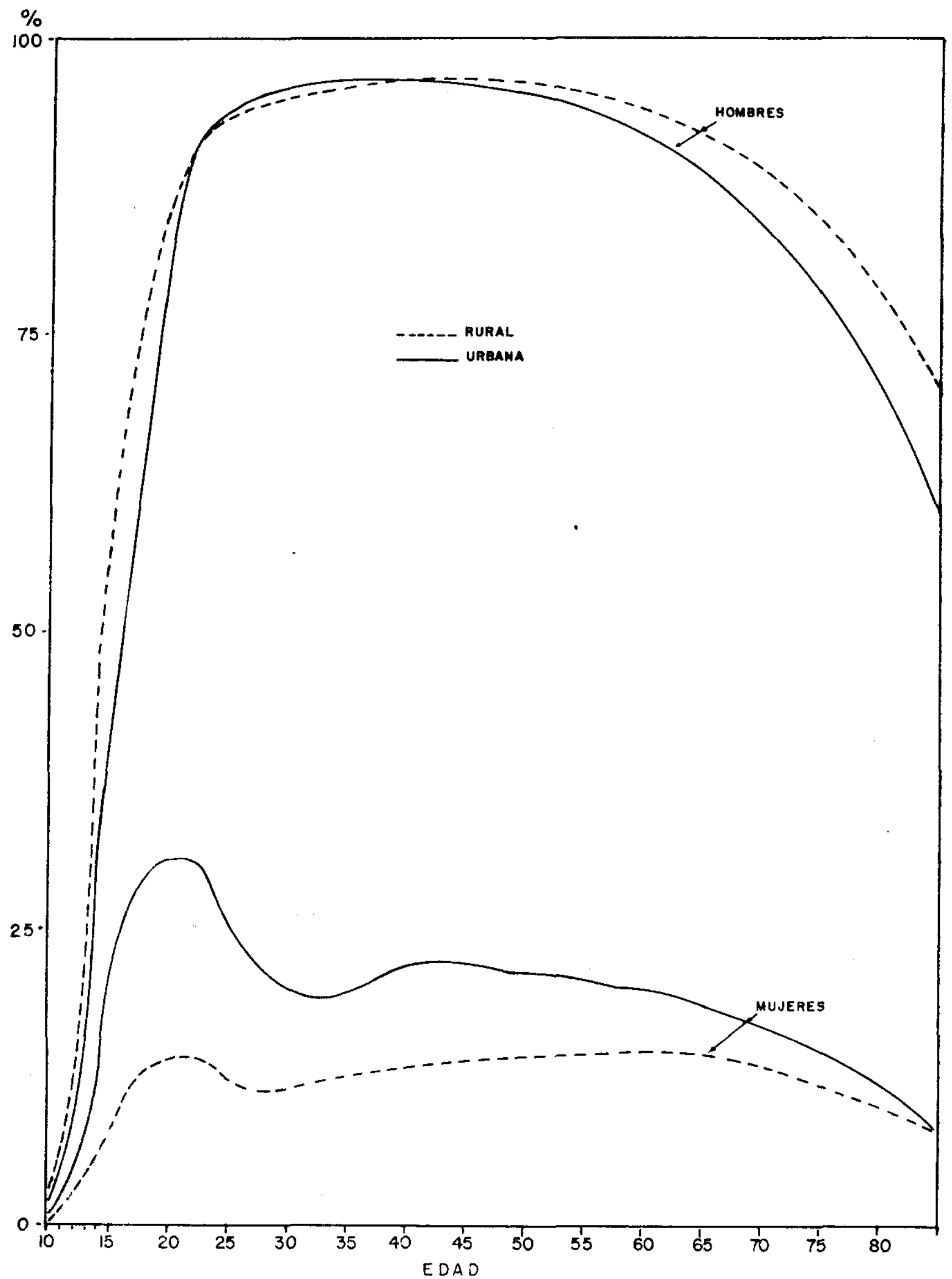

Fuente: Cuadro 3 (valores corregidos) del apéndice.

Gráfica 1

MÉXICO: PORCIENTO DE PARTICIPACIÓN POR EDAD, SEXO Y LUGAR DE RESIDENCIA, 1960 
empírica de otros países, y en la del propio México, en particular en algunas de sus entidades en que el proceso de urbanización e industrialización ha modificado la estructura ocupacional de la mano de obra. En el presente estudio sólo es posible determinar el efecto de la urbanización sobre la composición de la población por lugar de residencia (véase el cuadro 1): en 1960, la población activa urbana representaba el $52.3 \%$ de la población activa total y en 1965 el $56.6 \%$.

\section{Cuadro 1}

México: Población activa, PoR SeXo y lugar de Residencia, 1960 y 1965 (En miles)

\begin{tabular}{|c|c|c|c|c|c|c|}
\hline & \multicolumn{3}{|c|}{1960} & \multicolumn{3}{|c|}{1965} \\
\hline & Total & Hombres & Mujeres & Total & Hombres & Mujeres \\
\hline Total & 10826.6 & .8869 .2 & 1957.4 & 12734.9 & 10392.3 & 2342.6 \\
\hline Urbana & 5660.3 & 4335.3 & 1325.0 & 7203.4 & 5534.8 & 1668.6 \\
\hline Rural & 5166.3 & 4533.9 & 632.4 & 5531.5 & 4857.5 & 674.0 \\
\hline
\end{tabular}

Fuente: Cuadros A-5 y A-6 del apéndice II.

ENTRADAS A LA ACTIVIDAD, Y SALIDAS POR RETIRO Y DEFUNCIÓN, POR EDAD, SEXO Y LUGAR DE RESIDENCIA, 1960-1965

Entradas. Considerada la población activa como un subconjunto de un conjunto más general que es la población total, es posible establecer una similitud, pero con significado diferente, entre los componentes de cambio en ambas poblaciones. En la población total los componentes de cambios son: los nacimientos, las defunciones y las migraciones. En la población activa son las entradas a la actividad y las salidas de la misma, así como las migraciones que afectan las entradas y las salidas. ${ }^{12}$

La característica principal de las entradas a la actividad de la población urbana masculina, en 1960 y 1965, es su juventud: la edad media de las personas que se incorporan a la actividad es de 15.4 años. Esta edad media baja de los que ingresan a la mano de obra está determinada por el elevado porciento de población que se incorpora a la actividad en las edades jóvenes: el $50.7 \%$ del total de las entradas ocurre antes de los 15 años de edad; el $94.3 \%$ ingresa antes de los 20 años.

Característica similar se observa en la población urbana femenina, aunque en este caso la incorporación en las edades señaladas anteriormente es, en términos relativos, mayor que en el caso de los hombres. El $73.2 \%$ del total de las entradas se registra antes de los 15 años de edad; el $97.7 \%$ antes de los 20 años.

Las características demográficas de la población urbana masculina y femenina en 1965 son las mismas, ya que se suponen niveles cons-

12 Véanse algunos aspectos metodológicos en el apéndice II. 
tantes de participación. No obstante, sus entradas a la actividad superan ya en este año a las de la población rural. En 1960, las entradas de la población masculina rural fueron $6.3 \%$ mayores que las urbanas; en 1965 estas últimas fueron $13.7 \%$ mayores que las rurales. Este cambio obedece a que en 1965 la población urbana contaba con mayor número de efectivos en las edades de ingreso que la rural.

Los ingresos a la actividad de la población masculina rural tienen un patrón de comportamiento similar al observado en el área urbana, pues predomina también la incorporación elevada a la actividad antes de los 15 y los 20 años. En ambos casos, los porcientos de incorporación son de $57.5 \%$ y de $94.3 \%$. Por el contrario los porcentajes de ingreso de la población femenina rural, en estas edades, son menores que los de la correspondiente urbana. Sin embargo, en la femenina rural el intervalo para la reincorporación a la actividad es más amplio y va de los 20 a los 64 años. Los elevados ingresos a la actividad de la población urbana y la rural están determinados en general por factores demográficos como la estructura por edad, y en particular por factores económicos y sociales. Estos últimos determinan el comportamiento diferencial de dichas poblaciones entre ambas áreas. La incorporación a edades jóvenes presenta el problema de la escasez de mano de obra calificada, y su corolario: el excedente de mano de obra no calificada. Para equilibrar y mejorar esta situación será necesaria una reestructuración del sistema educativo en función de las exigencias que plantea la demanda de mano de obra, a fin de que la oferta se adapte a estas necesidades, y en lugar de un freno al desarrollo sea un factor decisivo del mismo. ${ }^{13}$ La reestructuración del sistema educativo supondrá, por lo tanto, una prolongación de la escolaridad, la elevación de las tasas de retención, la formación de técnicos de nivel medio y alto, todo lo cual, además de mejorar la calidad de la mano de obra, influirá en la incorporación a la actividad a edades más tardías. Los cambios en la composición por edad de las entradas de la población femenina, además de lo anteriormente indicado, dependerán del diferimiento de la edad de casamiento, de su actitud frente a la utilización de métodos anticonceptivos $\mathrm{y}$, en consecuencia, de la reducción del número de hijos tenidos, lo que a su vez, a largo plazo, influirá en la estructura por edades de la población que, desde el punto de vista demográfico, es una de las determinantes de la entrada a edades jóvenes.

Salidas por retiro. Con exclusión de la escolaridad, los demás factores económicos y sociales señalados en el caso de las entradas influyen en la mayor o menor permanencia de la población en actividad. En la población masculina, las salidas por retiro u otras causas, excepto defunción, se inician en el área urbana a partir de los 40 años. El máximo de las salidas por retiro $(32.1 \%)$ se da en el último grupo de edad ( 80 y más años), lo que a su vez determina una edad media relativamente elevada ( 69.6 años) de la población que se retira de la

13 Nino Novacco, "Métodos de previsión del empleo por sectores de actividad", cap. XII de OCDE, L'éducation et le dévéloppement économique et social, París, 1964. 
actividad. En la población urbana femenina, el máximo de las salidas de la actividad (48.7\%) se da entre las edades de 25-29 años. A partir de los 45 años, los retiros tienen características similares a los de los hombres. La edad media de la población femenina, calculada a partir de los 45 años, es también elevada (65.9 años).

Los mayores niveles de participación de la población rural masculina y el inicio del retiro a edad más tardía (45-49 años) contribuyen a la elevación de la edad media de la población rural que se retira de la actividad, que es de 74.1 años. El máximo de las salidas por retiro $(81.6 \%)$ de la población femenina se da entre los 20-29 años.

Salidas por defunción. La principal causa de salida de la actividad en la población masculina urbana y rural son las defunciones, que superan en todas las edades a los retiros. En la población femenina de ambas áreas, son también la principal causa de salida de la actividad, con excepción de las salidas que se producen en las edades jóvenes, en las que los retiros superan a las muertes.

Al comparar las salidas de la actividad a partir de los 60 años en Estados Unidos y México, se advierte que en el primero ${ }^{14}$ las salidas por retiro superan a las por defunción, mientras que en México estas últimas son la principal causa de separación de la actividad. Una explicación probable de este hecho en el caso de México sería: a) la estructura de la mortalidad; b) la insuficiencia de los programas de seguridad social, y $c$ ) la mayor proporción de la población dedicada a actividades agrícolas, donde la flexibilidad de la actividad permite la participación en actividad de personas que han alcanzado edades avanzadas.

Todas las características que se han mencionado en relación con las entradas y salidas de la actividad en 1960 y 1965 se mantienen al analizar los promedios de las mismas, ya que se han considerado niveles constantes de participación.

El cuadro 2 resume los resultados del análisis efectuado.

INCREMENTO DE LA POBLACIÓN ACTIVA POR SEXO Y LUGAR

DE RESIDENCIA, 1960-1965

El incremento de la población activa está determinado por el excedente de las entradas sobre las salidas, por lo cual la tasa de incremento sólo se refiere al crecimiento natural de la población activa pero no al incremento total. Para determinar este último sería necesario introducir tasas de migración.

El crecimiento diferencial entre el área urbana y la rural está determinado por la tasa más elevada de mortalidad en el área rural, cuyo efecto es disminuir las tasas medias de incremento en ésta, no obstante ser los niveles de entrada muy similares en ambas áreas. (Véase el cuadro 3.)

En el área urbana como en la rural, las tasas de incremento femeninas son mayores que las de los hombres. En el área urbana, pro-

14 Stuart Garfinkle, "Changes in Working Life of Men, 1900-2000", en Spengler y Duncan, op. cit., pp. 104-107. 


\section{Cuadro 2}

México: Movimiento medto anUal de entradas a la Actividad, Y DE Salidas por netiro y defunción, por edad, SeXo Y LUGAR DE RESIDENCIA, 1960-1965

$$
\text { (En miles) }
$$

\begin{tabular}{|c|c|c|c|c|c|c|c|c|c|c|c|c|}
\hline \multirow{4}{*}{$\begin{array}{l}\text { Gru- } \\
\text { pos } \\
\text { de } \\
\text { eded }\end{array}$} & \multicolumn{6}{|c|}{ Población activa urbana } & \multicolumn{6}{|c|}{ Población activa rural } \\
\hline & \multicolumn{3}{|c|}{ Hombres } & \multicolumn{3}{|c|}{ Mujeres } & \multicolumn{3}{|c|}{ Hombres } & \multicolumn{3}{|c|}{ Mujeres } \\
\hline & \multirow{2}{*}{$\begin{array}{c}\text { Entra- } \\
\text { das }\end{array}$} & \multicolumn{2}{|c|}{ Salidas } & \multirow{2}{*}{$\begin{array}{c}\text { Entra- } \\
\text { das }\end{array}$} & \multicolumn{2}{|c|}{ Selidas } & \multirow{2}{*}{$\begin{array}{l}\text { Entra- } \\
\text { das }\end{array}$} & \multicolumn{2}{|c|}{ Salidas } & \multirow{2}{*}{$\begin{array}{c}\text { Entra- } \\
\text { das }\end{array}$} & \multicolumn{2}{|c|}{ Salidas } \\
\hline & & $\begin{array}{c}\text { Ret1- } \\
\text { ro }\end{array}$ & $\begin{array}{l}\text { Defun- } \\
\text { c1ón }\end{array}$ & & $\begin{array}{c}\text { Ret1- } \\
\text { ro }\end{array}$ & $\begin{array}{c}\text { Defun- } \\
\text { c1ón }\end{array}$ & & $\begin{array}{c}\text { Ret1- } \\
\text { ro }\end{array}$ & $\begin{array}{l}\text { Defun- } \\
\text { c1ón }\end{array}$ & & $\begin{array}{l}\text { Ret1- } \\
\text { ro }\end{array}$ & $\begin{array}{l}\text { Defun- } \\
\text { clón }\end{array}$ \\
\hline Total & 208.05 & 11.41 & 44.78 & 73.40 & 13.62 & 9.20 & 199.05 & 8.3 .8 & 56.70 & 30.63 & 5.23 & 6.43 \\
\hline $\begin{array}{l}10-11 \\
11-12 \\
12-13 \\
13-14 \\
14-15\end{array}$ & $\begin{array}{r}8.25 \\
11.70 \\
14.85 \\
27.25 \\
43.15\end{array}$ & & 0.18 & $\begin{array}{r}3.50 \\
4.45 \\
7.05 \\
12.55 \\
25.70\end{array}$ & & 0.10 & $\begin{array}{l}10.40 \\
12.50 \\
15.15 \\
28.75 \\
47.40\end{array}$ & & 0.65 & $\begin{array}{l}2.25 \\
2.55 \\
2.50 \\
3.00 \\
4.85\end{array}$ & & 0.00 \\
\hline $15-19$ & 90.90 & & 1.23 & 27.75 & & 0.46 & 73.65 & & 2.54 & 12.70 & & 0.36 \\
\hline $\begin{array}{l}20-24 \\
25-20\end{array}$ & 8.40 & & 2.30 & & 2.54 & 0.61 & 7.45 & & 3.17 & & 1.38 & 0.47 \\
\hline $25-29$ & 2.75 & & 2.41 & & 7.72 & 0.47 & 2.25 & & 3.50 & & 2.86 & 0.40 \\
\hline $30-34$ & 0.60 & & 2.42 & & 1.1 .0 & 0.44 & 0.85 & & 3.87 & 0.66 & & 0.41 \\
\hline $35-39$ & 0.30 & & 2.50 & 2.05 & & 0.49 & 0.45 & & 4.10 & 0.78 & & 0.43 \\
\hline $40-4 \overline{4}$ & & 0.06 & 2.68 & 0.35 & & 0.53 & 0.20 & & 4.07 & 0.58 & & 0.43 \\
\hline $45-49$ & & 0.42 & 2.92 & & 0.19 & 0.55 & & 0.08 & 4.03 & 0.39 & & 0.41 \\
\hline $50-54$ & & 0.94 & 3.42 & & 0.30 & 0.67 & & 0.51 & 4.11 & 0.22 & & 0.43 \\
\hline $55-59$ & & 1.02 & 3.68 & & 0.33 & 0.78 & & 0.67 & 4.37 & 0.12 & & 0.50 \\
\hline $60-64$ & & 1.12 & 4.06 & & 0.29 & 0.90 & & 0.70 & 4.63 & 0.03 & & 0.56 \\
\hline $65-69$ & & 1.52 & 4.27 & & 0.28 & 0.94 & & 0.76 & 4.48 & & 0.09 & 0.55 \\
\hline $70-74$ & & 1.42 & 4.02 & & 0.24 & 0.92 & & 0.69 & 4.17 & & 0.18 & 0.51 \\
\hline $75-79$ & & 1.16 & 3.53 & & 0.23 & 0.47 & & 0.67 & 3.59 & & 0.18 & 0.37 \\
\hline 80. y + & & 3.75 & 5.26 & & 0.40 & 0.87 & & 4.10 & 5.42 & & 0.54 & 0.54 \\
\hline
\end{tabular}


bablemente obedezcan a la incorporación de mujeres a la actividad a edades más jóvenes, a las mayores oportunidades de empleo (industrias caseras, servicios domésticos, etc.) o bien a cambios culturales y sociales vinculados tanto al papel que desempeña la mujer en la sociedad urbana como a la opinión que se tenga en la misma sobre el trabajo femenino. En el área rural, además de la incorporación a edades jóvenes, el intervalo más largo de reincorporación a la actividad determina su mayor tasa de aumento.

Los coeficientes de reemplazo expresan en forma concisa el número de personas que entran a la actividad y el de las que salen. Además de dar una idea del ritmo de incremento de la población activa, hacen posible cuantificar la presión demográfica sobre el mercado

\section{Cuadro 3}

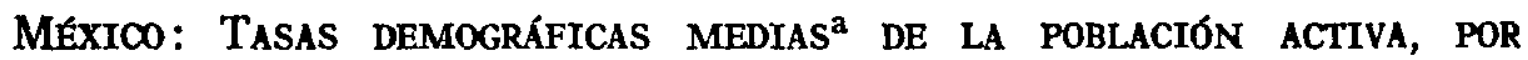
SEXO Y LUGAR DE RESIDENCIA, 1960-1965

\begin{tabular}{|c|c|c|c|c|c|c|c|c|c|}
\hline \multirow[b]{2}{*}{ Concepto } & \multicolumn{3}{|c|}{ Urbana } & \multicolumn{3}{|c|}{ Rural } & \multicolumn{3}{|c|}{ Total } \\
\hline & Total & $\begin{array}{l}\text { Hom- } \\
\text { bres }\end{array}$ & $\begin{array}{c}\text { Muje- } \\
\text { res }\end{array}$ & Total & $\begin{array}{l}\text { Hom- } \\
\text { bres }\end{array}$ & $\begin{array}{c}\text { Muje- } \\
\text { res }\end{array}$ & Total & $\begin{array}{l}\text { Hom- } \\
\text { bres }\end{array}$ & $\begin{array}{l}\text { Muje } \\
\text { res }\end{array}$ \\
\hline $\begin{array}{l}\text { Tasa de ac- } \\
\text { tividad }\end{array}$ & 30.7 & 48.2 & 14.0 & 29.0 & 49.6 & 7.3 & 29.9 & 48.9 & 10.9 \\
\hline $\begin{array}{l}\text { trada } \\
\text { Tasa de sa- }\end{array}$ & 43.7 & 42.1 & 49.0 & 42.9 & 42.4 & 46.9 & 43.4 & 42.3 & 48.4 \\
\hline $\begin{array}{l}\text { Iida } \\
\text { Retiro } \\
\text { Defunción }\end{array}$ & $\begin{array}{r}12.3 \\
3.9 \\
8.4\end{array}$ & $\begin{array}{r}11.4 \\
2.3 \\
9.1\end{array}$ & $\begin{array}{r}1.5 .2 \\
9.1 \\
6.1\end{array}$ & $\begin{array}{r}14.3 \\
2.5 \\
11.8\end{array}$ & $\begin{array}{r}13.8 \\
1.7 \\
12.1\end{array}$ & $\begin{array}{r}17.8 \\
8.0 \\
9.8\end{array}$ & $\begin{array}{r}13.2 \\
3.3 \\
9.9\end{array}$ & $\begin{array}{r}12.5 \\
2.0 \\
10.5\end{array}$ & $\begin{array}{r}16.1 \\
8.8 \\
7.3\end{array}$ \\
\hline $\begin{array}{l}\text { Tasa de in- } \\
\text { cremento } \\
\text { Coeficiente } \\
\text { de reempla } \\
\text { zo }\end{array}$ & 31.4 & 30.7 & 322.0 & 300.0 & 28.6 & 263.0 & 329.0 & 29.8 & 302.0 \\
\hline
\end{tabular}

Fuente: cuadros A-5 y A-6 del apéndice II.

a Las definiciones de las tasas son:

Tasa de entrada $=\frac{\text { entradas } \times 1000}{\text { PEA }} \quad$ Tasa de salida $=\frac{\text { salidas } \times 1000}{\text { PEA }}$

Tasa de incremento $=\frac{(\text { entradas }- \text { salidas }) \times 1000}{\text { PEA }}$

Coeficiente de reemplazo $=\frac{\text { entradas } \times 100}{* \text { salidas }}$

Tasa de actividad $=\frac{(\mathrm{PEA}) \times 100}{\text { población total }}$ 
de trabajo. De acuerdo con este indicador, en el área urbana, por cada persona que sale de la actividad por defunción o retiro, se incorporan en promedio 3.6 personas, mientras que en la rural la relación es de 1 a 3. Esta mayor proporción en el área urbana implica la necesidad de realizar esfuerzos adicionales tanto por lo que respecta a las inversiones productivas como a las inversiones sociales.

\section{DURACIÓN DE LA vida ACTIVA, 1960}

Por último, se hará un breve análisis del número promedio de años de vida activa (esperanza de vida activa o vida media activa) que espera tener un trabajador que se incorpora a la actividad a una edad dada. La vida media activa toma en cuenta tanto la edad a la que una persona se incorpora a la actividad como la edad a que se retira. Este indicador, analizado conjuntamente con la esperanza de vida, permite determinar el número promedio de años que una persona pasará en inactividad. $\mathrm{Y}$, al igual que la esperanza de vida, es un índice de las condiciones económicas y sociales de un país, porque refleja en forma concisa los adelantos que se han realizado: por un lado, el número de años en inactividad se amplía con la incorporación a la actividad a edades más avanzadas (menos jóvenes), lo que se logra a medida que el país se industrializa; por otro, el retiro a edades menos avanzadas es consecuencia de la extensión y operatividad de los programas de seguridad social, resultantes a su vez del desarrollo económico y social.

Para poder cuantificar los logros obtenidos es necesario contar

\section{Cuadro 4}

MÉXICO: VIDA MEDIA Y VIDA ACTIVA MEDIA DE LA POBLACIÓN POR SEXO Y LUGAR DE RESIDENCIA, 1960

(En años)

\begin{tabular}{|c|c|c|c|c|c|c|c|c|}
\hline \multirow[b]{3}{*}{ Edad } & \multicolumn{4}{|c|}{ Urbana } & \multicolumn{4}{|c|}{ Rural } \\
\hline & \multicolumn{2}{|c|}{ Hombres } & \multicolumn{2}{|c|}{ Mujeres } & \multicolumn{2}{|c|}{ Hombres } & \multicolumn{2}{|c|}{ Mujeres } \\
\hline & $\begin{array}{l}\text { Vida } \\
\text { media }\end{array}$ & $\begin{array}{l}\text { Vida } \\
\text { activa } \\
\text { media }\end{array}$ & $\begin{array}{l}\text { Vida } \\
\text { media }\end{array}$ & $\begin{array}{c}\text { Vida } \\
\text { activa } \\
\text { media }\end{array}$ & $\begin{array}{l}\text { Vida } \\
\text { media }\end{array}$ & $\begin{array}{l}\text { Vida } \\
\text { activa } \\
\text { media }\end{array}$ & $\begin{array}{l}\text { Vida } \\
\text { media }\end{array}$ & $\begin{array}{l}\text { Vida } \\
\text { activa } \\
\text { media }\end{array}$ \\
\hline $\begin{array}{l}10 \\
15 \\
20 \\
30 \\
40 \\
50 \\
60 \\
70\end{array}$ & $\begin{array}{l}57.61 \\
52.93 \\
48.43 \\
39.87 \\
31.51 \\
23.59 \\
16.42 \\
10.46\end{array}$ & $\begin{array}{r}54.46 \\
49.76 \\
45.23 \\
36.57 \\
28.05 \\
20.24 \\
13.27 \\
7.56\end{array}$ & $\begin{array}{l}59.86 \\
55.19 \\
50.59 \\
36.63 \\
33.09 \\
24.74 \\
17.14 \\
10.92\end{array}$ & $\begin{array}{r}20.35 \\
15.45 \\
10.55 \\
8.04 \\
6.22 \\
4.31 \\
2.63 \\
1.35\end{array}$ & $\begin{array}{l}52.99 \\
48.80 \\
44.62 \\
36.72 \\
29.52 \\
22.76 \\
16.45 \\
20.95\end{array}$ & $\begin{array}{l}50.98 \\
46.75 \\
42.54 \\
34.52 \\
27.12 \\
20.23 \\
13.93 \\
8.43\end{array}$ & $\begin{array}{l}55.64 \\
51.42 \\
47.21 \\
39.35 \\
31.77 \\
24.34 \\
17.30 \\
11.63\end{array}$ & $\begin{array}{r}15.86 \\
11.05 \\
6.18 \\
5.17 \\
4.32 \\
3.35 \\
2.32 \\
1.37\end{array}$ \\
\hline
\end{tabular}

Fuente: Vida media: Benítez Zenteno y Cabrera, op. cit.

Vida activa media: cálculos del autor. 
con información retrospectiva; en el caso actual no es posible hacerlo ya que se han supuesto niveles de mortalidad y actividad constantes durante el período analizado. En cambio, este análisis es factible hacerlo a nivel de áreas (urbanas y rurales), por existir entre ellas características diferenciales en mortalidad, en actividad y en condiciones económico-sociales.

Se supone a priori que la población masculina urbana registra mayor número de años en inactividad que la rural. Esto se corrobora al analizar el cuadro 4. De acuerdo con esta información, una persona en el área urbana que se incorporase a la actividad a los 10 años pasaría en inactividad 3.15 años, mientras que en el área rural pasaría en tal condición 2.01 años. Si ingresara a los 20 años, de los 48.4 años que una persona urbana espera vivir en promedio, pasaría en actividad el $93.3 \%$; en el área rural, pasaría en actividad el $95.3 \%$ de los 44.6 años que espera vivir.

En la población femenina, por el contrario, es la mujer rural la que pasaría más años en inactividad. Si a los 10 años se incorporara una mujer rural a la actividad, pasaría 39.8 años en inactividad; la mujer urbana tendría 39.5 años en esa condición.

A medida que se avanza en la edad la diferencia en los años en inactividad va siendo mayor. Esto se debe a la reducción más rápida de la esperanza de vida de la población urbana y a la existencia de mayores niveles de participación en la misma. Además de estos factores, influyen también la distribución del estado civil, la edad de casamiento, el número de hijos tenidos y las mayores oportunidades de empleo de la mujer en las áreas urbanas. Sin embargo, para poder determinar el efecto de algunos de estos factores sería necesario elaborar tablas de vida activa femeninas según su estado civil. En el caso presente, la principal explicación de los diferenciales en inactividad entre el área urbana y la rural son la estructura de la mortalidad y los niveles de participación. Como los niveles de participación de la población rural femenina son relativamente bajos, su esperanza de vida activa es menor y en consecuencia acusa mayor número promedio de años en inactividad.

Por último, al comparar los niveles de la esperanza de vida activa según lugar de residencia, puede suponerse que a medida que disminuya la mortalidad se lograrán aumentos en la vida activa media del trabajador. Estos aumentos serían relativamente menores que los de la esperanza de vida si se prolongara la escolaridad, pues el efecto de esto último sería diferir la edad de incorporación a la actividad; y lo mismo ocurrirá, pero en menor grado, si el retiro se realiza a edades no tan avanzadas. De la prolongación de la vida activa se derivarían ventajas económicas, aun cuando podrían quedar contrarrestadas si el crecimiento de la proporción de la población dependiente fuese mayor que el incremento experimentado por la vida activa.

\section{CONCLUSIONES}

Los movimientos de entrada y salida de la población activa total (hombres y mujeres) entre 1960 y 1965 se resumen como sigue: 


\begin{tabular}{lccc}
\hline & Area urbana & Area rural & Total \\
\hline Entradas & 281500 & 229700 & 511200 \\
Salidas & 79000 & 76500 & 155500 \\
Retiro & 25000 & 13400 & 38400 \\
Defunción & 54000 & 63100 & 117100 \\
Entradas netas & 202500 & 153200 & 355700 \\
\hline
\end{tabular}

Fuente: Cuadro 2.

De las 281500 personas que en promedio se incorporan anualmente a la actividad en al área urbana, corresponde a los hombres el $73.9 \%$ y a las mujeres el $26.1 \%$. De las 79000 personas que salieron de la actividad, el $71.1 \%$ fueron hombres y el resto mujeres.

En el área rural, de los 229700 que ingresaron a la actividad, el $86.7 \%$ fueron hombres. De las 76500 que se retiraron, el $15.0 \%$ correspondió a las mujeres.

Considerando únicamente las entradas se necesitarían crear en promedio 511200 nuevos empleos cadà año. Pero tomando el saldo neto $\mathrm{y}$ suponiendo que las vacantes son llenadas automáticamente se necesitarían crear sólo 355700 plazas. Esta conclusión adquiere mucha importancia en vista de la frecuente aseveración en declaraciones tanto oficiales como privadas de que México "necesita crear 450000 (o 500000 ) nuevos empleos cada año". Además de no tomar en cuenta las salidas o bajas, esa cifra no considera la estructura por edad.

Tomando en cuenta el coeficiente de reemplazo se observa que la presión demográfica es mayor en el área urbana, ya que por cada 100 personas que salen de la actividad por muerte o retiro se incorporan 356 (cuadro 3). En el área rural ingresan 56 personas menos que en la urbana. Otra forma de comparar este mismo aspecto es analizando las tasas de incremento en ambas áreas. En el área urbana, la tasa de incremento es de 31.4 por mil y en la rural de 28.6 por mil (cuadro 3). Si se toman en cuenta las corrientes migratorias, la tasa de incremento urbano sería más elevada y mayor por lo tanto la necesidad de crear nuevos empleos en esa área. Si el proceso de urbanización continúa, aun cuando la fecundidad disminuya, el crecimiento de la población activa urbana, en los próximos años, seguirá siendo mayor por efectos de la migración y sobre todo por el potencial de crecimiento acumulado en su joven estructura por edad.

Asimismo, la estructura joven de la población lleva lógicamente al rejuvenecimiento de la población activa. Esta característica obedece, además, a la incorporación a la actividad a edades jóvenes. Más del $90 \%$ de la población, en ambas áreas, se incorpora a la actividad antes de los 20 años (cuadro 2). Sin embargo, la estructura por edad de la población activa urbana está ligeramente más envejecida que la rural, probablemente por el efecto de la fecundidad y la migración diferenciales, y por esta razón la edad media de la población activa urbana es mayor $(16.7 \%)$ que la de la rural.

Otro aspecto importante es el hecho de que las salidas por retiros 
entre la población masculina se dan a edades avanzadas. Más del $60 \%$ ocurre a partir de los 65 años, tanto en el área urbana como en la rural (cuadro 2). Además, las salidas por defunción son, por lo general, la principal causa de separación en todas las edades, lo que contrasta con lo observado en países más desarrollados, por ejemplo, Estados Unidos, ${ }^{15}$ donde entre los 60 y los 72 años la causa principal de separación es el retiro y no la defunción.

Lo anterior se explica por los mayores niveles de participación de la población mexicana en las edades avanzadas. Igualmente, la existencia de niveles diferenciales de participación en estas edades entre el área urbana y la rural explica el retiro de la actividad de un número mayor de personas en la primera área que en la segunda.

Las diferencias tanto en las tasas de participación como en las de mortalidad, explican también las registradas en la esperanza de vida activa entre la población urbana y la rural.

Finalmente, aunque no es propósito de este trabajo hacer una caracterización del subdesarrollo a través del análisis de la población económicamente activa, algunas de las características aquí mencionadas podrían utilizarse con este propósito. Por ejemplo, en los países industrializados los niveles de las tasas de participación en las edades marginales son inferiores a los que se observan en los países en proceso de desarrollo. Asimismo, la mayor proporción de la población en las edades jóvenes y adultas incide en la incorporación a la actividad a edades más tempranas en los países subdesarrollados que en los desarrollados; igualmente, la mayor permanencia en actividad en las edades adultas por insuficiencia de los programas de seguridad o por necesidad económica determina que la gente se retire a edades más avanzadas que en los países desarrollados. El número de años promedio en inactividad es mayor en los países desarrollados que en los países en proceso de desarrollo, debido a los más altos niveles de participación y a la estructura de la mortalidad. La sistematización y análisis de estas características entre ambos grupos de países aportaría más elementos de juicio para establecer una tipología más completa del subdesarrollo. En esta forma la demografía se sumaría a otras ciencias sociales en pro del esclarecimiento y mejor conocimiento de la realidad de nuestros países. ${ }^{16}$

\section{APÉNDICE I}

\section{EVALUACION DE LA CALIDAD Y REPRESENTATIVIDAD} DE LA MUESTRA

De acuerdo con el VIII Censo General de Población de 1960, la población activa censada fue de 11332016 personas, cifra que figura en el cuadro 27 del Resumen general, distribuida por sexo y grupos de edad. En este cuadro aparece que la población económicamente activa masculina a partir del grupo de edad de 25-29 es mayor que la pobla- 
ción total. Debido a esto, la Dirección General de Estadística publicó un Volumen especial en donde presentó una nueva distribución de la población activa, para hombres y mujeres, sin modificar el total general.

En el Volumen especial no se explica el error ni el procedimiento seguido para su corrección. Lo anterior tiene importancia porque al expandir la muestra del $1.5 \%$ de la población utilizada en este trabajo (elaborada por el Centro de Estudios Económicos y Demográficos de El Colegio de México), ésta representó un poco más del $85 \%$ de la cifra oficial y porque además, al analizar los resultados de las pruebas estadísticas (Chi-cuadrada y Kolmogorov-Smirnov), éstas indicaron que entre el Volumen especial y la muestra existían grandes diferencias, indicadoras de que no había correspondencia entre ambas fuentes de información.

De aquí surgen estas preguntas: ¿la corrección realizada en la población activa sería uno de los factores que expliquen las diferencias entre censo y muestra? $\mathrm{O}$ bien, ¿estas incongruencias son atribuibles al proceso de muestreo?

La primera pregunta se aclara en gran parte al comparar ambas informaciones. Al examinar el Resumen general y el Volumen especial, se encontraron algunas irregularidades en determinados grupos de edad (12-14 a 20-24). Por ejemplo, la cifra corregida del grupo 12-14 resultó mayor que la cifra original en un $93.6 \%$; aumentos menores (del orden del 30.0\%) se advierten en los grupos 15-19 y 20-24.

Teniendo en cuenta lo anterior, al enfrentar los resultados de las cifras corregidas y de las obtenidas a través de la muestra, se encontró que precisamente las discrepancias más notables se concentran en los grupos de edad anteriormente señalados. Estas fuertes discrepancias motivaron que al aplicar las diferentes pruebas estadísticas de confiabilidad de la muestra, no hubiera la correspondencia esperada entre las cifras corregidas y las de la muestra. ${ }^{1}$

Es difícil aceptar que la fuente de los errores de la población activa a partir de los 25 años sean los grupos de 12-14 a 20-24. Por el contrario, se cree que a los errores que originalmente contenía el cuadro 27 del Resumen General se sumaron los errores de la corrección, ya que ésta, según parece, se realizó sólo redistribuyendo los excedentes (a partir de los 25 años) en determinados grupos de edad (12-14 a 20-24).

En cuanto a la segunda pregunta, la respuesta se deriva de la anterior, debido a que si sólo se toma la población de más de 25 años las pruebas estadísticas arrojan resultados satisfactorios. De aquí que no se pueda aceptar que los errores, inherentes al sistema de muestreo empleado, sean de tal magnitud que invaliden la muestra; asimismo no es posible determinar éstos dados los errores que existen en las tabulaciones censales.

Por último, para tener más elementos de juicio que fundamenten la decisión de trabajar con la muestra, se realizó un análisis con criterios demográficos del comportamiento de las tasas de participación derivadas del Volumen especial y de los de la muestra. Para esto se

1 Se encontró que las tasas de participación de los grupos de 12-14 a 20-24 calculadas con la información sin corregir tenían niveles similares a los que se obtuvieron con la muestra. 


\section{Cuadro A-1}

México y otros países: TASAS DE ACTIVIdAd POR EDAD Y SEXo, 1950

\begin{tabular}{|c|c|c|c|c|c|c|c|}
\hline \multirow{2}{*}{$\begin{array}{l}\text { Gru- } \\
\text { pos } \\
\text { de } \\
\text { edad }\end{array}$} & \multicolumn{7}{|c|}{ Hombres } \\
\hline & $\begin{array}{l}\text { Indus- } \\
\text { triali } \\
\text { zados }\end{array}$ & $\begin{array}{l}\text { Semi- } \\
\text { indus- } \\
\text { triali } \\
\text { zados }\end{array}$ & $\begin{array}{c}\text { Agríco- } \\
\text { las }\end{array}$ & $\begin{array}{l}\text { Méxi- } \\
\text { co a }\end{array}$ & $\begin{array}{l}\text { Vene- } \\
\text { zuela }\end{array}$ & $\begin{array}{c}\text { Costa } \\
\text { Rica }\end{array}$ & $\begin{array}{c}\text { Pana- } \\
\text { má }\end{array}$ \\
\hline $\begin{array}{l}10-14 \\
15-19 \\
20-24 \\
25-34 \\
35-44 \\
45-54 \\
55-64 \\
65 y+\end{array}$ & $\begin{array}{r}4.1 \\
72.4 \\
91.5 \\
96.7 \\
97.6 \\
95.9 \\
85.6 \\
37.7\end{array}$ & $\begin{array}{l}13.2 \\
70.3 \\
91.8 \\
96.2 \\
97.1 \\
95.9 \\
88.9 \\
61.0\end{array}$ & $\begin{array}{l}23.9 \\
78.4 \\
91.2 \\
96.3 \\
97.5 \\
96.3 \\
91.6 \\
70.1\end{array}$ & $\begin{array}{l}15.0 \\
77.5 \\
94.6 \\
96.8 \\
97.3 \\
96.9 \\
96.1 \\
91.6\end{array}$ & $\begin{array}{l}21.3 \\
82.9 \\
94.7 \\
96.7 \\
96.8 \\
95.9 \\
91.6 \\
73.1\end{array}$ & $\begin{array}{l}37.4 \\
91.1 \\
96.7 \\
98.4 \\
98.6 \\
97.6 \\
94.8 \\
74.0\end{array}$ & $\begin{array}{l}17.4 \\
68.3 \\
94.8 \\
97.8 \\
98.2 \\
97.1 \\
89.6 \\
70.3\end{array}$ \\
\hline
\end{tabular}

Mujeres

Canadá Améri- Méxi- Vene- Costa Pana- Afri- Ceilán y E.U. ca la-co a/ zuela Rica má. ca del y Mala. tina Norte ya

$\begin{array}{rrrrrrrrr}10-14 & 0.6 & 5.5 & 2.5 & 5.42 & 5.0 & 5.3 & 8.6 & 13.3 \\ 15-19 & 32.1 & 25.3 & 16.7 & 34.06 & 22.5 & 23.4 & 38.2 & 31.2 \\ 20-24 & 45.0 & 25.8 & 19.3 & 35.08 & 22.6 & 29.6 & 39.3 & 35.1 \\ 25-24 & 28.0 & 20.5 & 15.8 & 28.89 & 17.2 & 25.2 & 41.3 & 36.4 \\ 35-44 & 28.4 & 19.6 & 18.7 & 26.67 & 15.7 & 24.6 & 42.6 & 40.2 \\ 45-54 & 26.6 & 17.7 & 23.6 & 21.75 & 13.3 & 20.8 & 38.8 & 38.6 \\ 55-64 & 19.0 & 14.0 & 28.3 & 16.71 & 9.1 & 15.0 & 32.9 & 29.9 \\ 65 y+ & 6.4 & 8.9 & 29.5 & 10.23 & 5.6 & 8.4 & 14.8 & 14.6\end{array}$

Fuentes: México: VIII Censo General de Población, 1960.

Otros: Naciones Unidas, Aspectos demográficos de la mano de obra, Estudios de población, Núm. 33, 1963; Naciones Unidas, Los recursos humanos en Panamá, Centroamérica y México, 1950-1980, 1963; E. Arriaga, Proyección de la población económicamente activa de Venezuela, 19501975, CELADE, Serie C, Núm. 26.

a 1960 .

compararon las tasas de participación de ambas fuentes con las observadas en otros países con igual o menor grado de desarrollo económico (véanse los cuadros $\mathrm{A}-1$ y $\mathrm{A}-2$ ). Los resultados de este análisis fueron: que las tasas de participación de la muestra presentan un comportamiento más regularizado que las del Volumen especial y que son más acordes, sobre todo en el caso de la población femenina, con los patrones observados en otros países. 


\section{Cuadro A-2}

MÉxico: TASAS DE ACTIVIDAd POR EDAD Y SEXo, DEL CENSO Y DE LA MUESTRA, 1960

\begin{tabular}{|c|c|c|c|c|c|c|c|c|}
\hline \multirow{2}{*}{$\begin{array}{c}\text { Grupos } \\
\text { de } \\
\text { edad }\end{array}$} & \multicolumn{4}{|c|}{ Hombres } & \multicolumn{4}{|c|}{ Mujeres } \\
\hline & Censo & & $\begin{array}{c}\text { Mues- } \\
\text { tra }\end{array}$ & & Censo & & $\begin{array}{c}\text { Mues- } \\
\text { tra }\end{array}$ & \\
\hline $8-11$ & $3.24]$ & & 2.601 & & $0.93]$ & & 0.801 & \\
\hline $\begin{array}{l}12-14 \\
15-19 \\
20-24 \\
25-29\end{array}$ & $\begin{array}{l}32.14 \\
77.50 \\
94.61 \\
96.661\end{array}$ & 15.0 & $\begin{array}{l}12.61 \\
59.18 \\
84.16 \\
91.52\end{array}$ & 7.85 & $\begin{array}{c}4.83 \\
16.72 \\
19.33 \\
15.619\end{array}$ & 2.5 & $\begin{array}{l}4.15 \\
13.95 \\
15.40 \\
12.021\end{array}$ & 2.5 \\
\hline $\begin{array}{l}30-34 \\
35-39\end{array}$ & $\left.\begin{array}{l}96.99 \\
97.31\end{array}\right\}$ & 96.8 & $\begin{array}{r}93.25 \\
93.661\end{array}$ & 92.32 & $\left.\begin{array}{l}15.99 \\
17.531\end{array}\right\}$ & 15.8 & $\begin{array}{l}11.74 \\
12.88\end{array}$ & 11.90 \\
\hline $\begin{array}{l}40-44 \\
45-49\end{array}$ & $\begin{array}{l}97.25 \\
97.22\}\end{array}$ & 97.3 & $\begin{array}{l}93.55 \\
94.141\end{array}$ & 93.62 & $\left.\begin{array}{l}20.39 \\
22.28\end{array}\right\}$ & 18.7 & $\left.\begin{array}{l}13.82 \\
14.54\end{array}\right\}$ & 13.27 \\
\hline $\begin{array}{l}50-54 \\
55-59\end{array}$ & $\begin{array}{l}96.56 \\
96.257\end{array}$ & 96.9 & $\begin{array}{l}93.28 \\
92.897\end{array}$ & 93.74 & $\left.\begin{array}{l}25.17 \\
26.04\end{array}\right\}$ & 23.6 & $\left.\begin{array}{l}14.51 \\
15.39\end{array}\right\}$ & 14.52 \\
\hline $\begin{array}{l}60-64 \\
65-69\end{array}$ & $\begin{array}{l}95.89 \\
94.32\end{array}$ & & $\begin{array}{l}91.001 \\
90.269\end{array}$ & & $\begin{array}{l}30.79 \\
30.131\end{array}$ & 20.3 & $\begin{array}{l}15.85 \\
15.99\end{array}$ & 13.01 \\
\hline $70 y+$ & & 91.0 & 79.50 & 02.21 & & 29.5 & 12.55 & 13.00 \\
\hline
\end{tabular}

Fuente: VIII Censo General de Población, 1960, y El Colegio de México, Centro de Estudios Económicos y Demográficos, muestra del $1.5 \%$ del VIII Censo General de Población, cuadro III-1, Población de ocho años y más, cconómicamente activa (agrícola y no agrícola) y no económicamente activa, por grupos de edad, sexo, urbana y rural, por actividades.

\section{Procedimiento de AJUSTE}

Para regularizar aun más las tasas de participación de la muestra éstas fueron ajustadas por diferentes procedimientos. En un principio se utilizó una media ponderada simple haciendo intervenir para esto algunas variables económicas. Sin embargo, los resultados que se obtuvieron en el caso de las tasas de participación de la población femenina rural no fueron satisfactorios ya que siguieron presentando algunas irregularidades. En su lugar, se decidió obtener estas tasas por otro procedimiento, que consistía en estimarlas por diferencia, entre la tasa de la población total y la de la urbana con su respectiva ponderación.

Para el procedimiento inicial las variables que se emplearon como 
ponderaciones fueron la urbanización y la industrialización, ${ }^{2}$ por la relación que existe entre ambas variables y entre éstas y la actividad. ${ }^{3}$

Con base en estos indicadores se seleccionaron las siguientes entidades que se consideraron representativas de la actividad económica existente en el área urbana y la rural y que sirven como guías para hacer la corrección (las entidades urbanas estuvieron representadas por las tres entidades cuyo índice de urbanización fue superior al nacional y las rurales por las tres entidades con niveles inferiores):

\begin{tabular}{lcc}
\hline & $\begin{array}{c}\text { Indice de } \\
\text { urbanización }\end{array}$ & $\begin{array}{c}\text { Indice de } \\
\text { industrialización }\end{array}$ \\
\hline Nacional & 30.0 & 45.8 \\
Distrito Federal & 72.6 & 96.9 \\
Nuevo León & 59.6 & 64.5 \\
Coahuila & 44.0 & 51.5 \\
Veracruz & 17.4 & 32.3 \\
Chiapas & 13.4 & 15.5 \\
Oaxaca & 7.8 & 14.3 \\
\hline
\end{tabular}

La relación que se usó fue:

$$
A_{x, x+4} ; m, u=1 / 2\left[\Sigma A_{x, x+4} ; m, u ; i\left(\delta_{x, x+4} ; m, u ; i+Y_{i}\right)\right]
$$

donde :

$A_{x, x+4} ; m, u=$ tasa de actividad ajustada de la población masculina urbana

$A_{x, x+4} ; m, u ; i=$ tasa de actividad urbana masculina del estado $i$

$\delta_{x, x+4} ; m, u ; i=$ índice de industrialización de la población masculina urbana del estado $i$

$$
Y_{i}=\text { índice de urbanización del estado } i
$$

En el caso de las tasas rurales femeninas el ajuste se efectuó utilizando la siguiente expresión:

$A_{x, x+4} ; f, r=\frac{A_{x, x+4}, f-A_{x, x+4} ; f, u\left(K_{x, x+4}, f\right)}{1-K_{x, x+4}, f}$

2 Como indicador de la urbanización se utilizó el índice propuesto por Davis, al que se define como el promedio aritmético de los porcientos de población de localidades de 5000 y más, 10000 y más, 20000 y más, 50000 y más y 100000 y más. Para mayor referencia véase: Kinsley Davis y Ana Casis: "Urbanization in Latin America" en Hatt y Reiss Jr. (compiladores) Cities and Societies, Nueva York, The Free Press of Glencoe, 1961, pp. 142-143. Para la industrialización se empleó el porciento de población activa en actividades no agrícolas. Este índice es más bien un indicador de las actividades urbanas que de industrialización. Sin embargo, con este significado se ha utilizado en diferentes estudios. Consúltese, por ejemplo, Naciones Unidas, Aspectos demográficos..., op. cit.

3 Naciones Unidas, Los recursos humanos en Panamá, Centroamérica y México, 1950-1980. ST/TAO/K/LAT/1, E/CN. 12/548. CEPAL, 1963, pp. 46-50. 
siendo:

$A_{x, \mathrm{x}+4} ; f, r=$ tasa de actividad de la población femenina rural

$A_{x, x+4} ; f=$ tasa de actividad total de la población femenina $A_{x, x+4} ; f, u=$ tasa de actividad de la población femenina urbana

$K_{x, x+4} ; f=$ proporción de población dedicada a la agricultura respecto a la población activa

En el cuadro A-3 aparecen las tasas de participación observadas y corregidas.

\section{Cuadro A-3}

MÉXICO: TASAS DE ACTIVIDAD OBSERVADAS Y CORREGIDAS, POR EDAD, SEXO Y LUGAR DE RESIDENCIA, 1960

\begin{tabular}{|c|c|c|c|c|c|c|c|c|}
\hline \multirow{3}{*}{$\begin{array}{c}\text { Grupos } \\
\text { de } \\
\text { edad }\end{array}$} & \multicolumn{4}{|c|}{ Urbano } & \multicolumn{4}{|c|}{ Rural } \\
\hline & \multicolumn{2}{|c|}{ Hombres } & \multicolumn{2}{|c|}{ Mujeres } & \multicolumn{2}{|c|}{ Hombres } & \multicolumn{2}{|c|}{ Mujeres } \\
\hline & $\begin{array}{l}\text { Obser- } \\
\text { vadas }\end{array}$ & $\begin{array}{l}\text { Corre- } \\
\text { gidas }\end{array}$ & $\begin{array}{l}\text { Obser- } \\
\text { vadas }\end{array}$ & $\begin{array}{l}\text { Corre- } \\
\text { gidas }\end{array}$ & $\begin{array}{l}\text { Obser- } \\
\text { vadas }\end{array}$ & $\begin{array}{l}\text { Corre- } \\
\text { gidas }\end{array}$ & $\begin{array}{l}\text { Obser- } \\
\text { vadas }\end{array}$ & $\begin{array}{l}\text { Corre- } \\
\text { gidas }\end{array}$ \\
\hline & & 0.0200 & 0.06 & & 0594 & 0.0300 & 0.0116 & \\
\hline & 0.0136 & 0.0550 & 0.0110 & 0.02 & .0691 & 0.0750 & 0.0164 & 0.0148 \\
\hline & 0.0368 & 0.0940 & 0.0268 & 0.0430 & .1222 & 0.1250 & 0.0238 & 0.0260 \\
\hline & 0.0734 & 0.1700 & 0.0434 & 0.0840 & .1836 & 0.2500 & 0.0252 & 0.0387 \\
\hline & 0.1814 & 0.3250 & 0.0936 & 0.1800 & 0.3224 & 0.4250 & 0.0387 & 0.0579 \\
\hline & 0.5076 & 0.6100 & 0.2219 & 0.2840 & .6715 & 0.7500 & 0.0533 & 0.1258 \\
\hline & 0.8217 & 0.9200 & 0.2496 & 0.3060 & 0.8611 & 0.9160 & 0.0502 & 0.1432 \\
\hline & 0.9212 & 0.9510 & 0.1846 & 0.2200 & 0.9095 & 0.9425 & 0.0493 & 0.1130 \\
\hline & 0.9442 & 0.9625 & 0.1721 & 0.1940 & .9208 & 0.9550 & 0.0517 & 0.1207 \\
\hline & 0.9525 & 0.9670 & 0.1902 & 0.2075 & 0.9205 & 640 & 0.0589 & 0.1290 \\
\hline & 0.0487 & 0.9660 & 0.1993 & 0.2233 & 0.9221 & 0.9660 & 0.0695 & 0.1363 \\
\hline & 0.950 & 0.9600 & 0.2004 & 0.2149 & 0.9313 & 0.9650 & 0.0793 & 0.1400 \\
\hline & 0.9408 & 0.9490 & 0.1960 & 0.2130 & 0.9241 & 0.9600 & 0.0830 & 0.1421 \\
\hline & 0.9347 & 0.9300 & 0.1965 & 0.2026 & 0.9231 & 0.9500 & 0.1004 & 0.1456 \\
\hline & 0.9041 & & 0.1893 & 0.1967 & 0.9139 & 0.9300 & 0.1211 & 0.1472 \\
\hline & 0.9030 & 0.8700 & 0.1877 & 0.1724 & 0.9036 & 0.9050 & 0.1221 & 0.1407 \\
\hline & 0.8315 & 0.8170 & 0.1722 & 0.1580 & 0.8830 & 0.8700 & 0.1159 & 0.1280 \\
\hline & 0.7807 & 0.7500 & 0.1439 & 0.1316 & 0.8801 & 0.8200 & 0.0985 & 0.1075 \\
\hline & 0.6347 & 0.6000 & 0.1 .140 & 0.0800 & 0.7533 & 0.7090 & 0.0879 & 0.0850 \\
\hline
\end{tabular}

Fuente: El Colegio de México, CEED, muestra del 1.5\% del VIII Censo General de Población, cuadro III-1. 


\section{APÉNDICE II}

\section{ESTIMACION DE LAS ENTRADAS A LA ACTIVIDAD Y DE LAS SALIDAS}

Las entradas están constituidas por el conjunto de personas que a partir de una edad dada se incorporan a la actividad. Las salidas las forman todas aquellas personas que se retiran de la actividad por defunción, vejez, retiro profesional y otras causas de menor importancia.

Como en México no existen registros estadísticos que proporcionen información directa sobre las entradas a la actividad y las salidas, hay que recurrir a métodos indirectos para su obtención. De los indirectos el más elaborado es la tabla de vida activa. Sin embargo, no es necesario construir la tabla de vida activa para estimarlas, debido a que se pueden obtener como función de las tasas de actividad a edades exactas. Estas relaciones se demuestran de la siguiente forma:

En la tabla de vida activa ${ }^{4}$ la tasa de entrada a la actividad se define por

siendo:

$$
{ }_{n} m_{x}^{i a}=\frac{{ }_{n} h_{x}^{i a}}{{ }_{n} L_{x}}
$$

$$
\begin{aligned}
{ }_{n} m_{x}^{i a}= & \text { tasa de entrada a la actividad entre las edades } x \mathrm{y} x+n \\
{ }_{n} h_{x}^{i a}= & \text { número total de personas que entran a la actividad } \\
& \text { en la población estacionaria } \\
{ }_{n} L_{x}= & \text { número de años vividos por las personas entre las eda- } \\
& \text { des } x \text { y } x+n \\
{ }_{n} h_{x}^{i a}= & 1 / 2\left(l_{x}^{i a}+l_{x}^{i a} p_{x}\right)
\end{aligned}
$$

donde:

$l_{x}^{i a}=$ número de sobrevivientes inactivos a la edad exacta $x$, que pasan a la categoría de activos al alcanzar la edad $x+n$

${ }_{n} p_{x}=\frac{l_{x+n}}{l_{x}}=\begin{aligned} & \text { probabilidad que tiene una persona de edad } x \text { de llegar } \\ & \text { con edad } x+n\end{aligned}$

y

$$
{ }_{n} L_{x}=n / 2\left(l_{x}+l_{x+n}\right)
$$

siendo:

$l_{x}=$ número de sobrevivientes a la edad exacta $x$

$l_{x+n}=$ número de sobrevivientes a la edad exacta $x+n$

4 J. Somoza, Tabla de vida activa. CELADE, Santiago de Chile, 1966. Serie 3, núm. 26 (edición provisional). 
Finalmente:

$$
l_{x}^{i a}=\frac{l_{x+n}^{a}-l_{x n} p_{x}}{{ }_{n} p_{x}}
$$

siendo :

$l_{x+n}^{a}=l_{x+n} \cdot a_{x+n}=$ número de sobrevivientes activos a la edad exacta $x+n$

$$
\begin{aligned}
a_{x+n} & =\text { tasa de actividad a la edad exacta } x+n \\
\iota_{x}^{a}=l_{x} a_{x} & =\text { número de sobrevivientes activos a la edad exacta } x \\
a_{x} & =\text { tasa de actividad a la edad exacta } x
\end{aligned}
$$

Reemplazando (3) en (1):

$$
{ }_{n} h_{x}^{i a}=1 / 2\left[\frac{l_{x+n}^{a}-l_{x} \cdot{ }_{n} p_{x}+\cdot l_{x+n}-l_{x} \cdot{ }_{n} p_{x}}{{ }_{n} p_{x}}\right]
$$

de donde

$$
\frac{{ }_{n} h_{x}^{i a}}{{ }_{n} L_{x}}=\frac{1 / 2\left(l_{x}+l_{x+n}\right)\left(a_{x+n}-a_{x}\right)}{n / 2\left(l_{x}+l_{x+n}\right)}
$$

luego

$$
\frac{{ }_{n} h_{x}^{i a}}{{ }_{n} L_{x}}=\frac{a_{x+n}-a_{x}}{n}
$$

Con esta última expresión se demuestra que las tasas de entrada son función de las tasas de actividad a edades exactas, con lo cual se simplifica su cálculo. En este caso, sólo es necesario hacer una interpolación entre las tasas centrales de actividad para obtener los valores de las tasas de actividad a edades exactas.

En la misma forma se puede demostrar lo anterior respecto a la tasa de salida por retiro que se define por:

$$
{ }_{n} m_{n}^{a i}=\frac{{ }_{n}^{a i} h_{x}}{{ }_{n} L_{x}}
$$

donde :

$$
\begin{aligned}
{ }_{n} h_{x}^{a i}= & \text { tasa de salida por retiro de la actividad entre las eda- } \\
& \text { des } x \text { y } x+n \\
{ }_{n} h_{x}^{a i}= & \text { número total de personas que salen de la actividad en } \\
& \text { la población estacionaria }
\end{aligned}
$$


Siguiendo el mismo procedimiento se demuestra que:

$$
{ }_{n} m_{x}^{a i}=\frac{{ }_{n} h_{x}}{{ }_{n} L_{x}}=\frac{a_{x}-a_{x+n}}{n}
$$

Por último, la tasa de salida por defunción se define por:

$$
\begin{aligned}
{ }_{n} m_{x}^{d}= & \frac{{ }_{n} d_{x}^{a}}{{ }_{n}^{a} L_{x}^{a}} \\
{ }_{n} d_{x}^{a}= & \begin{array}{l}
\text { defunciones de la población activa entre las edades } \\
x \text { y } x+n
\end{array} \\
{ }_{n} L_{x}^{a}= & \text { número medio de años vividos por las personas acti- } \\
& \text { vas entre las edades } x \text { y } x+n
\end{aligned}
$$

La aplicación del método simplificado se basa en las siguientes consideraciones: existe mortalidad diferencial por sexos, edad y lugar de residencia, quedando representadas estas diferenciales por los valores de la esperanza de vida que aparecen a continuación:

\begin{tabular}{|c|c|c|c|c|}
\hline \multirow[b]{2}{*}{ Movimiento } & \multicolumn{2}{|c|}{ Población urbana } & \multicolumn{2}{|c|}{ Población rural } \\
\hline & Hombres & Mujeres & Hombres & Mujeres \\
\hline Entradas & $\begin{array}{l}\text { Hasta los } \\
40 \text { años }\end{array}$ & $\begin{array}{l}\text { Hasta los } \\
20 \text { años y } \\
\text { entre los } \\
35 \text { y los } 45 \\
\text { años }\end{array}$ & $\begin{array}{l}\text { Hasta los } \\
45 \text { años }\end{array}$ & $\begin{array}{l}\text { Hasta los } \\
20 \text { años y } \\
\text { entre los } \\
30 \text { y los } 65 \\
\text { años }\end{array}$ \\
\hline $\begin{array}{l}\text { Salidas por } \\
\text { retiro }\end{array}$ & $\begin{array}{l}\text { A partir } \\
\text { de los } 40 \\
\text { años }\end{array}$ & $\begin{array}{l}\text { De los } 20 \\
\text { hasta antes } \\
\text { de los } 35 \\
\text { años y a } \\
\text { partir de } \\
\text { los } 45 \text { años }\end{array}$ & $\begin{array}{l}\text { A partir } \\
\text { de los } \\
45 \text { años }\end{array}$ & $\begin{array}{l}\text { De los } 20 \\
\text { hasta antes } \\
\text { de los } 30 \\
\text { años y a } \\
\text { partir de } \\
\text { los } 65 \text { años }\end{array}$ \\
\hline $\begin{array}{l}\text { Salidas por } \\
\text { defunción }\end{array}$ & \multicolumn{4}{|c|}{$\begin{array}{l}\text { Afectan a todas las edades y se supone que no existe } \\
\text { mortalidad diferencial entre población activa y pobla- } \\
\text { ción total }\end{array}$} \\
\hline
\end{tabular}

ESPERANZA DE VIDA AL NACER

\begin{tabular}{ccccc}
\hline Periodo & Hombres & Mujeres & Hombres & Rural \\
\hline $1960-1965$ & 60.14 & 63.50 & 51.57 & Mujeres \\
\hline
\end{tabular}

Fuente: Benítez Zenteno y Cabrera, op. cit., tablas II y IV, pp. 92, 93, 96 y 97.

Los supuestos adoptados para estimar las entradas y salidas pueden verse en forma clara en el siguiente cuadro: 
Los supuestos mencionados tienen un carácter operacional y no reflejan del todo la realidad. En ésta, las entradas y las salidas se dan a lo largo de la curva, por lo que sería más conveniente hablar de movimientos netos. El supuesto de igual mortalidad en la población total y en la activa sobrestima la mortalidad de esta última. Es más, no sólo existe mortalidad diferencial entre ésta y la población total sino también según la posición en la ocupación..$^{5}$ La falta de este tipo de información no permite establecer hipótesis más adecuadas.

Las tasas de entrada y de salida estimadas aparecen en el cuadro A-4.

5 J. C. Elizaga, Mortalidad. CELADE, Santiago de Chile, 1966, Serie B, núm. 10, pp. 124-131. 


\section{Cuadro A-4}

México: Tasas anuales de entrada a la actividad y de salida, población uRbana y RURal, por edad y SEXo, $1960-1965$

\begin{tabular}{|c|c|c|c|c|c|c|c|c|c|c|c|c|}
\hline \multirow{3}{*}{$\begin{array}{l}\text { Grupos } \\
\text { de } \\
\text { edad }\end{array}$} & \multicolumn{6}{|c|}{ Población urbana } & \multicolumn{6}{|c|}{ Población rural } \\
\hline & \multicolumn{3}{|c|}{ Hombres } & \multicolumn{3}{|c|}{ Mujeres } & \multicolumn{3}{|c|}{ Hombres } & \multicolumn{3}{|c|}{ Mujeres } \\
\hline & $\begin{array}{l}\text { Tasa de } \\
\text { entrada }\end{array}$ & $\begin{array}{c}\frac{\text { Tasa }}{\text { Reti }} \\
\text { ro }\end{array}$ & $\frac{e \text { salida }}{\text { Defun- }}$ clón & $\begin{array}{l}\text { Tasa de } \\
\text { entrada }\end{array}$ & $\begin{array}{c}\frac{\text { Tasa }}{\text { Reti }} \\
\text { ro }\end{array}$ & $\begin{array}{l}\text { de salida } \\
\text { Defun- } \\
\text { ción a }\end{array}$ & $\begin{array}{l}\text { Tasa de } \\
\text { entrada }\end{array}$ & $\begin{array}{c}\frac{\text { Tasa }}{\text { Reti }} \\
\text { ro }\end{array}$ & 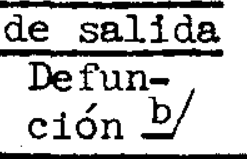 & $\begin{array}{l}\text { Tasa de } \\
\text { entrada }\end{array}$ & $\begin{array}{c}\frac{\text { Tasa }}{\text { Ret1 }} \\
\text { ro }\end{array}$ & 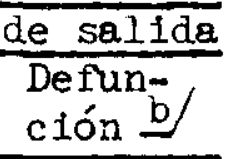 \\
\hline 10-11 & 0.0300 & & & .0130 & & ] & .0400 & & ) & .0093 & & ) \\
\hline $11-12$ & 0.0450 & & & .0170 & & & .0500 & & & .0110 & & \\
\hline $12-13$ & 0.0600 & & .001154 & .0280 & & 3.001138 & .0630 & & $\$ .003179$ & .0113 & & $\$ .002929$ \\
\hline $13-14$ & 0.1150 & & & .0520 & & & .1250 & & & .0142 & & \\
\hline $14-15$ & 0.1900 & & & .1100 & & & .2150 & & & .0242 & & \\
\hline $15-19$ & 0.0900 & & .001996 & .0168 & & .001522 & .0764 & & .003505 & .0145 & & .003192 \\
\hline $20-24$ & 0.0100 & & .002955 & & .0028 & .002165 & .0098 & & .004565 & & .0019 & .004495 \\
\hline $25-29$ & 0.0040 & & .003629 & & .0100 & .002721 & .0035 & & .005867 & & .0045 & .005477 \\
\hline $30-34$ & 0.0010 & & .004187 & & .0016 & .003360 & .0016 & & .007632 & .0012 & & .006339 \\
\hline $35-39$ & 0.0005 & & .005090 & .0036 & & .004108 & .0010 & & $: 009463$ & .0017 & & .007382 \\
\hline $40-44$ & & .000 & .006559 & .0008 & & .005024 & .0006 & & .011382 & .0016 & & .008549 \\
\hline $45-49$ & & .0024 & .008805 & & .0010 & .006612 & & .0002 & .013751 & .0013 & & .009951 \\
\hline $50-54$ & & .0033 & .012506 & & .0018 & .009611 & & .0020 & .016847 & .0010 & & .012303 \\
\hline $55-59$ & & .0043 & .016441 & & .0024 & .013917 & & .0030 & .021363 & .0007 & & .016836 \\
\hline $60-64$ & & .006 & .025107 & & .0028 & .021436 & & .0040 & .028155 & .0002 & & .024015 \\
\hline $65-69$ & & .0118 & .036961 & & .0036 & .054718 & & .0060 & .039394 & & .0007 & .034670 \\
\hline $70-74$ & & .0160 & .056014 & & .0044 & .052406 & & .0080 & .055138 & & .0019 & .050561 \\
\hline $75-79$ & & .0208 & .084889 & & .0064 & .049081 & & .0120 & .079619 & & .0032 & .071036 \\
\hline $80 \mathrm{y}+$ & & .0706 & .165813 & & .0110 & .156801 的 & & .0790 & $.149681 \mathrm{c}$ & & .0120 & .1395360 \\
\hline
\end{tabular}

a Tabla de vida, grupo II, en Benítez Zenteno y Cabrera, op. cit.

b Tabla de vida, grupo IV, ibid,

c Se calculó con base en la siguiente relación: $\frac{\sum_{80}^{\infty} n^{d} \mathrm{x}}{T_{80}}$ 


\section{Cuadro A-5}

MÉxico: EFectivos activos, Y Movimiento DE ENTRAdA A La ACTIVIDAD Y SALIDA, POR EDAD, SEXO Y LUGAR DE RESIDENCIA, 1960

(En miles)

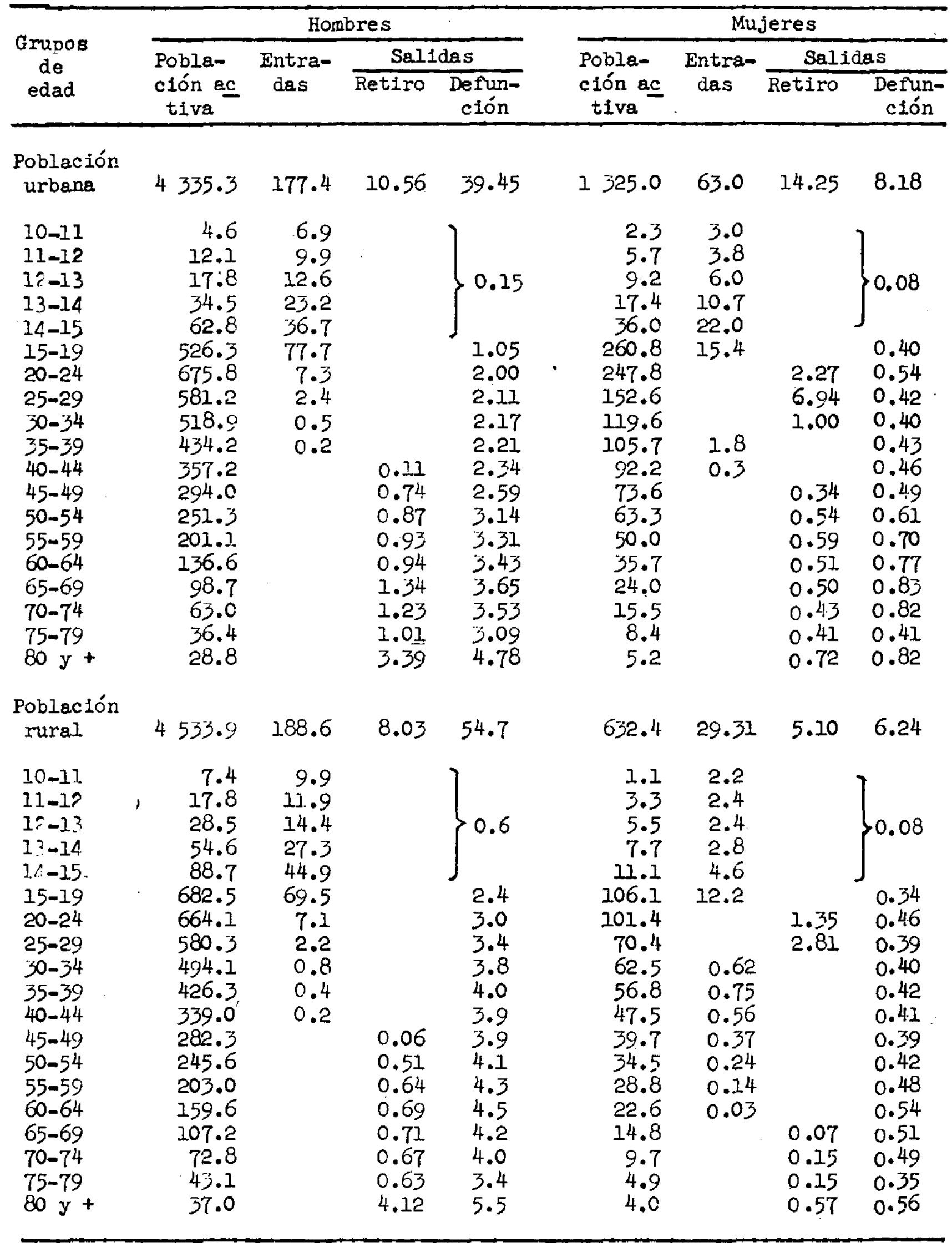

Fuente: Elaboraciones del autor, con base en las cifras de población corregidas de Benítez Zenteno y Cabrera, op. cit., y los cuadros A-3 (cifras corregidas) у A-4. 


\section{Cuadro A-6}

MÉxico: EFectivos activos, Y MOvimiento DE ENTRADA a LA actividad Y SALIDA, POR EDAD, SEXO Y LUGAR DE RESIDENCIA, 1965

(En miles)

\begin{tabular}{|c|c|c|c|c|c|c|c|c|}
\hline \multirow{3}{*}{$\begin{array}{l}\text { Grupos } \\
\text { de } \\
\text { edad }\end{array}$} & \multicolumn{4}{|c|}{ Hombres } & \multicolumn{4}{|c|}{ Mujeres } \\
\hline & \multirow{2}{*}{$\begin{array}{l}\text { Efecti } \\
\text { vos ac } \\
\text { tivos }\end{array}$} & \multirow{2}{*}{$\begin{array}{c}\text { Entra- } \\
\text { das }\end{array}$} & \multicolumn{2}{|c|}{ Salidas } & \multirow{2}{*}{$\begin{array}{l}\text { Efecti } \\
\text { vos ac } \\
\text { tivos }\end{array}$} & \multirow{2}{*}{$\begin{array}{c}\text { Entra- } \\
\text { das }\end{array}$} & \multicolumn{2}{|c|}{ Salidas } \\
\hline & & & Retiro & $\begin{array}{l}\text { Defun- } \\
\text { ción }\end{array}$ & & & Retiro & $\begin{array}{l}\text { Defun- } \\
\text { ción }\end{array}$ \\
\hline $\begin{array}{c}\text { Población } \\
\text { urbana }\end{array}$ & 5534.8 & 238.7 & . $1 \bar{j} .1$ & 49.94 & 1668.6 & 83.8 & $17 \cdot 3$ & 10.15 \\
\hline $\begin{array}{l}10-11 \\
11-12 \\
12-13 \\
13-14 \\
14-15\end{array}$ & $\begin{array}{r}6.3 \\
16.5 \\
26.8 \\
46.6 \\
84.9\end{array}$ & $\begin{array}{r}9.4 \\
13.5 \\
17.1 \\
31.3 \\
49.6\end{array}$ & & 0.21 & $\begin{array}{r}3.1 \\
7.8 \\
12.4 \\
23.3 \\
48.1\end{array}$ & $\begin{array}{r}4.0 \\
5.1 \\
8.1 \\
14.4 \\
29.4\end{array}$ & & 0.11 \\
\hline $15-19$ & 705.8 & 204.1 & & 1.40 & 339.6 & 20.1 & & 0.52 \\
\hline $20-24$ & 875.3 & 9.5 & & 2.59 & 308.1 & & 2.8 & 0.67 \\
\hline $25-29$ & 745.4 & 3.1 & & 2.71 & 186.6 & & 8.5 & 0.51 \\
\hline $30-34$ & 634.5 & 0.7 & & 2.66 & 144.2 & & 1.2 & 0.48 \\
\hline $35-39$ & 547.2 & & & 2.79 & 133.6 & 2.3 & & 0.55 \\
\hline $40-4 i$ & 460.0 & & 0.1 & 3.02 & 119.8 & 0.4 & & 0.60 \\
\hline $45-49$ & 368.8 & & 0.9 & 3.25 & 91.8 & & 0.4 & 0.61 \\
\hline $50-54$ & 295.0 & & 1.0 & 3.69 & 75.3 & & 0.6 & 0.72 \\
\hline $55-59$ & 245.6 & & 1.1 & 4.04 & 60.9 & & 0.7 & 0.85 \\
\hline $60-64$ & 186.7 & & 1.3 & 4.69 & 48.0 & & 0.7 & 1.03 \\
\hline $65-69$ & 127.0 & & 1.7 & 4.69 & 30.2 & & 0.6 & 1.05 \\
\hline $70-74$ & 81.1 & & 1.6 & 4.50 & 19.4 & & 0.5 & 1.02 \\
\hline $75-79$ & 46.7 & & 1.3 & 3.97 & 70.6 & & 0.5 & 0.52 \\
\hline $80 y+$ & 34.6 & & 4.1 & 5.73 & 5.8 & & 0.8 & 0.91 \\
\hline $\begin{array}{c}\text { Población } \\
\text { rural }\end{array}$ & 4857.5 & 209.5 & 8.2 & 58.29 & 674.0 & 31.93 & 5.3 & 6.31 \\
\hline $10-11$ & 8.2 & 10.9 & & 7 & 1.2 & 2.3 & & 7 \\
\hline $11-12$ & 19.7 & 13.1 & & & 3.6 & 2.7 & & \\
\hline $12-13$ & 31.5 & 15.9 & & 0.69 & 6.1 & 2.6 & & 0.09 \\
\hline $13-14$ & 60.5 & 30.2 & & & 8.6 & 3.2 & & \\
\hline $14-15$ & 98.6 & 49.9 & & & 12.2 & 5.1 & & J \\
\hline $15-19$ & 763.8 & 77.8 & & 2.68 & 114.9 & 13.2 & & 0.37 \\
\hline $20-24$ & 729.9 & 7.8 & & 3.35 & 105.6 & & 1.4 & 0.47 \\
\hline $25-29$ & 611.1 & 2.3 & & 3.59 & 72.8 & & 2.9 & 0.40 \\
\hline $30-34$ & 514.4 & 0.9 & & 3.93 & 66.5 . & 0.7 & & 0.42 \\
\hline $35-39$ & 444.1 & 0.5 & & 4.20 & 60.1 & 0.8 & & 0.44 \\
\hline $40-44$ & 371.4 & 0.2 & & 4.23 & 52.9 & 0.6 & & 0.45 \\
\hline $45-49$ & 301.5 & & 0.1 & 4.15 & 43.5 & 0.4 & & 0.43 \\
\hline $.50-54$ & 244.4 & & 0.5 & 4.12 & 35.0 & 0.2 & & 0.43 \\
\hline $55-59$ & 207.5 & & 0.7 & 4.43 & 30.4 & 0.1 & & 0.51 \\
\hline $60-64$ & 168.6 & & 0.7 & 4.75 & 24.3 & 0.03 & & 0.58 \\
\hline $65-69$ & 120.7 & & c. 8 & 4.75 & 27.1 & & 0.1 & 0.59 \\
\hline $70-74$ & 78.5 & & 0.7 & 4.33 & 10.4 & & 0.2 & 0.53 \\
\hline $75-79$ & 47.4 & & 0.7 & 3.77 & 5.4 & & 0.2 & 0.38 \\
\hline $80 \mathrm{y}+$ & 35.7 & & 4.0 & 5.34 & 3.7 & & 0.5 & 0.52 \\
\hline
\end{tabular}

Fuente: Elaboración del autor con base en las cifras de población proyectada (1965) de Benítez Zenteno y Cabrera, op. cit., y los cuadros A-3 (cifras corregidas) y A-4. 